Book Review

\title{
David Taras and Christopher Waddell (2020). The End of the CBC? University of Toronto Press, 240 pages.
}

Review by Simon St-Denis, University of Ottawa

The End of the CBC?, written by David Taras, Ralph Klein Chair in Media Studies at Mount Royal University, and Christopher Waddell, professor at Carleton University's School of Journalism and Communication, reads like a multi-faceted essay on the factors and influences that have led to the decline of the Canadian Broadcasting Corporation's (CBC) revenue, presence in the broadcasting sphere, and perhaps most important of all, influence in shaping the cultural identity of Canadians. Across the eight chapters featured in this book, the authors seek to inform and educate readers about the events that have diminished the relevance of Canada's public broadcaster over the last seven decades, recounting its trials and tribulations through a well-researched, apolitical lens.

Are we witnessing the end of the $\mathrm{CBC}$ ? Already a bold question to frame the Issue of public broadcasting in Canada, the book opens with a chapter on the political and media environment that culminated in the creation of the $\mathrm{CBC}$, as a radio broadcasting company which, two decades later, expanded into the cable television industry. The authors go on to discuss the external pressures from private broadcasters as well as from the Canadian Radio-television and Telecommunications Commission (CRTC) which hampered the CBC's growth into television broadcasting, and they demonstrate how this growth was further hindered by the CBC's tenuous position as a media entity under the control of government. A whole chapter is dedicated to this last point, underlining the frictions between Canadian political leadership through successive governments of different political affiliations, and the mandate of the CBC: to reflect Canadian identity, to address its audiences as citizens rather than consumers, and to provide a service intended to serve the public good (p. 3). This mandate has put the broadcasting corporation at odds with what individual federal leaders have thought public broadcasters should stand for and how they should operate (p. 37). By virtue of controlling both the appointment of the company's executive staff and the federal 
budget (p. 29) allotted to the CBC who had barely any external sources of revenue, political leaders were able to slowly throttle its activities to a mere shadow of their former glory (pp. 38-41).

The fourth chapter of this book tackles a topic that will be of particular interest to anyone with an interest in media studies: the fragmentation of audiences and the attention economy. The digital era has brought with it big changes in the media landscape caused by the sheer amount of content produced and distributed on the internet. Audiences for any channel or TV program are becoming increasingly fragmented and thus shrinking, as many of these individual sources of content are competing for the same people, the same eyeballs. Concurrent changes to the ways in which media is consumed - in great quantity but often without much depth or commitment - means that content producers of all kinds are also vying for consumers' attention. It is made clear that the authors believe the CBC could hold a niche if it was allocated the funds required and allowed to grow into a competitive force in the digital market with their new streaming platform, CBC Gem.

Later chapters cover the loss of the CBC's flagship program Hockey Night in Canada, its struggles with news broadcasting, its as of yet notable but limited success in the digital market, and what may have seemed like the CBC's final hope (pp. 140146) in the form of their Creative Canada proposal which was completely sidelined by ex-Minister of Heritage Mélanie Joly's cultural-policy review document on the future of public broadcasting in Canada. The book closes with a somewhat hopeful assessment of the $\mathrm{CBC}$ 's future prospects and recommendations for overhauling the current structure and priorities of the corporation. "The CBC", the authors say, "cannot recapture its past glories in sports, music, children's TV or [...] in comedy and drama. [...] [w] hat [they] believe is required is a bold restructuring of the mandate role, and place of the CBC in Canada's universe" (p.116) as well as a shift in funding sources, amongst other changes that would see the CBC focus on specializing into particular areas of the media industry. Removing advertising revenue entirely would free up the CBC journalists to think differently about news and current affairs without the pressures of impressing advertisers for revenue.

As a whole, Taras and Waddell's book reads coherently, with one argument flowing into the other. The reader can clearly grasp the sequence of arguments and how different elements coincide with each other. By presenting the state of affairs and the factors that are holding the CBC back, the authors enable the reader to reach similar conclusions as are presented in the final chapter. Forty-four pages of notes and bibliographic references' worth of concurring facts and statements from experts in the field, as well as numbers sourced mainly from government or private corporation 
reports are extensively cited throughout the book, providing context and weight to the arguments presented therein. The authors, though uncertain about the future of public broadcasting in Canada, seem to favor the idea of a country in which the CBC retains a central place in the cultural media landscape - although markedly different from the one it held in its heyday.

Taras and Waddell have done a masterful job of delivering in a neutral tone their work which incorporates the perspectives of key stakeholders in the debate surrounding the need for public broadcasting in Canada: the private corporations, the CBC itself, and the federal government to a lesser extent. They provide a culturally relevant case study for concepts in communications such as audience fragmentation, attention economy, cord-cutting, streaming, journalism in the digital age, and more. Not content to simply educate and describe, The End Of The CBC? also offers policy recommendations for the $\mathrm{CBC}$ 's programming focus and content. It's worth noting that while the authors at times discuss the CBC's French language counterpart, RadioCanada, the text mostly focuses on the circumstances that have led to the CBC's current state of affairs. Radio-Canada is treated as a separate entity due to the unique linguistic and cultural differences that have come to shape and define it. This book contains vital information and perspectives for anyone with a vested interest in the future of the $\mathrm{CBC}$ as an organization able to provide accessible, high quality content in the current media environment to citizens across the country. With hope, the contents of this book will make their way into the minds of those academics, policy-makers, journalists, and members of the public that can spark much needed change in Canada's current media landscape. 